\title{
The Ability of Top Management Team on Enterprise Innovation Development
}

\author{
Yuqi Zhang ${ }^{\text {a }}$, Lu Mab \\ School of Management, Guangxi University of Science and Technology, Liuzhou 545006, China \\ a523078471@qq.com, bmalu6655@163.com
}

Keywords: top management team, ability, development.

\begin{abstract}
Top management team is the main enterprise strategic decision makers, the constitution of the team decided to its highest in the enterprise strategy formulation and execution layer, is responsible for the entire enterprise's organization and coordination, there is a big decision for enterprise management and control group of top managers. The top management team plays an important role in enterprise development. This paper combs and summarizes the basic concept of top management team and its relationship with enterprise development by sorting out the existing literature in China and the west, and puts forward its own opinions. Based on the above results, the author puts forward effective Suggestions on the development of enterprises, and hopes to play a certain role in the development of enterprises.
\end{abstract}

\section{Introduction}

One of the things that keeps the economy going is innovation, and the main enabler of technological innovation and technological advances is enterprise. Therefore, the management and economic fields have always put the innovation of enterprises as hot spots. Hambrick \& Mason (1984) based on higher-order theory put forward by the finiteness of the senior management team as the main body of enterprise strategic decision, the behavior and characteristics influence the enterprise innovation behavior and organizational performance. In these studies, scholars have explored the age, heterogeneity, gender, degree of education in the top management team. Amason and Sapienza (2001) think that the increased heterogeneity of the top management team is good for the quality of decisionmaking [1]. According to the existing research, the cognition of top managers is influenced by the heterogeneity of the functional background of the team. In other words, the top management team with diversified functional background is more sensitive to the change of external environment, so the top management team is more aware of the independent innovation and will give more attention spontaneously. However, with the development of the research, the demographic characteristics of the executive team and the impact of the heterogeneity on the impact of the development of the enterprise, the researchers began to focus on the ability of the top management team to have a more direct impact on the development of corporate innovation.

$\mathrm{Hu}$ et al. (2013) believe that one of the core competencies of the top management team is its reasonable and efficient [2]. Under the driving force of economic globalization, the competition of market uncertainty is intensifying. In order to make fast and accurate decisions in a complex economic environment, which is conducive to the economic development of enterprises, the technology and ability of individual managers are not expected. In this situation, the collective intelligence and comprehensive ability of the top management team has become an excellent way to solve problems. According to dynamic capabilities, the absorption of learning new skills can make the enterprise gain competitive advantage, and organizational learning and absorbing new skills depend on the degree of individual learning efficiency and study its members, everyone in the team's learning and absorbing ability and formed a team of absorptive capacity. According to the management of the senior management team, the position of the enterprise products in the industrial chain is determined by management, so that the enterprise can generate path dependence. However, through the accumulation of previous enterprises, enterprises have a keen observation of new markets, choose the right way to develop the products, and then carry out the production of products and the series of 
management activities resulting from them. In the cycle, enterprises form the core competitiveness, which also has an obvious positive effect on the sustainable development of enterprises. In the process of this development, the ability of top management team has played a vital role for enterprise innovation and development. Based on this, the researchers began to focus on the competence of the executive team and its impact on enterprise development. Based on the definition of the competence of the top management team, this study analyzes the influence of the general ability and knowledge management ability of the senior management team on the innovation and development of the enterprise, and gives some enlightenment to the theoretical research and management practice of the top management team.

\section{The Ability of Top Management Team}

\subsection{Basic Concept}

Wang (2015) believed that the ability of the top management team is not equal to the sum of the individual abilities of the employees [3]. He combined the concept of enterprise top management team and management ability, and defined the ability of senior management team to embody and reflect the ability of the members in the senior management team, namely the skills, knowledge and other implicit abilities required by the members of the executive team in the management of the enterprise, as well as the ability of personality traits, emotions and other hidden abilities. These include skills, leadership, decision-making, internal and cognitive abilities. Benoliel (2016) defined the capability of top management team as the ability to control the overall production and operation of enterprises [4].

The stronger the top management team members are, the better the overall capability of the top management team, and the quality of the strategic decisions made by the top management team, which in turn will facilitate the development of the enterprise.

\subsection{Mechanism}

Innovation is a new concept, and its importance lies in its impact on the company's outstanding performance and market success. However, the two steps of innovation are difficult to develop and implement in practice [5]. This is because, to achieve exploration and development, it is necessary to effectively manage the internal differences of the company's basic resources, assets, strategic direction and entrepreneurial process. In general, research shows that firms need to think about a variety of factors to make a better innovation. There are two things to emphasize: the first emphasis on strategic direction as a guiding principle, which affects decision style, strategy implementation, and business operations, and the second is associated with human resources management based on management capacity.

Management ability refers to the ability of managers to build, integrate, and reorganize the organization's resources and capabilities. These capabilities enable senior management teams to meet their environment, improve organizational performance, and maintain and create competitive advantages. Working in a changing environment requires companies to explore new knowledge and resources needed for radical innovation, while leveraging existing knowledge and resources to achieve incremental innovation that requires managerial competence.

Human resource management based on management capabilities can be conceptualized as a set of management strategies and activities that enable employees to develop their skills and knowledge and ultimately contribute to competitive advantage. It is thought that human resource management based on management capability can foster an organizational environment that can be effectively explored and developed through recruiting, participation and learning mechanisms based on management capabilities.

First of all, to build a supportive environment, it is important to choose and maintain the ability to explore new knowledge and improve existing knowledge based on ability. People who choose to share knowledge will also increase innovation, because they are better able to contribute to new knowledge by sharing knowledge [6]. Therefore, consistent with the premise of strategic human resource management, the recruitment practice based on management ability needs to ensure that the individual ability is closely related to the company's innovation activities or norms. 
Second, learning is the core of innovation. Through flexible training system, learning mechanism is established [7]. This system promotes an environment where employees can access various abilities and skills development opportunities, which enables them to explore and develop at the same time. The learning agility of the employees, coupled with their multi-skill abilities, encourages the flexibility of the firm's human resources management. It is this dynamic capability that facilitates the pursuit of exploration and development while strengthening the innovation capability of employees and enterprises.

In addition, research shows that for small and medium-sized enterprises in science and technology, management ability is an effective resource, which can improve their innovation performance by helping them better manage their resources and capabilities and better cope with various restrictions. Companies need managers to use their resources and money to innovate and react to the rapid and intermittent changes in their environment [8]. In this case, the outcome of product and process innovation is critical to the company's survival and success. Some studies emphasize that the difference between management in the technology industry, and the difference between success and development in terms of success and development, is a big part of success and development in terms of innovation. Therefore, for small and medium-sized enterprises in the field of science and technology, the impact of enterprise innovation on executives' management ability is more obvious. In addition, small and medium-sized enterprises have more resource constraints than large enterprises, and the management support system of their decision-making process is less developed. The research of Kearney et al. (2006) shows that the management ability of small companies has maintained the development of innovation, because these abilities can better encourage the use of interaction and resources, so as to promote employee innovation [9]. Therefore, small enterprises are more dependent on management ability to achieve success.

In general, the management ability of the top management team is an important factor affecting the innovation of enterprises, especially for small and medium-sized enterprises. And the management ability promotion innovation can be realized through the human resource management practice based on management ability. In general, for better promotion of enterprise innovation, the enterprise needs to enhance the management capability of the executive team and implement it through human resource management practices, which reflect the importance and promotion of innovation.

\section{Conclusions and Future Perspective}

\subsection{Conclusions}

The high-performance executive team is one of the company's core competencies and has a profound impact on the development of the enterprise. The ability of the top management team is the focus and reflection of team members' ability, rather than the simple addition of individual ability. Therefore, the improvement of top management team ability needs not only the ability of individual members, but also the cooperation among members rather than loss, so as to achieve the goal of "1+1>2" [10]. The management of the top management team, as an effective resource for the enterprise, can be used to better manage their resources in a better way, by helping them to better manage their resources, to improve their creative performance. In addition, the knowledge management ability of the top management team is also an important factor, because the knowledge management ability of the top management team has a more direct and far-reaching influence on enterprise innovation.

By combing relevant literatures, this paper analyzes the important role of the general management ability top management team on the innovation and development of enterprises. It can be found that enterprises can enhance their innovation ability through the following aspects.

First of all, the research results show that the dimensions of innovation performance is affected by the management ability is not the same, so the enterprise to cultivate the students' management ability, not blind without purpose, but should be according to their own situation, purposeful targeted deployment knowledge management strategy. For example, when the enterprise's product innovation performance is relatively low, the enterprise should comprehensively enhance the dynamic 
knowledge management ability, especially the cultivation of knowledge innovation ability. And when the enterprise cooperative innovation performance is low, the enterprise must strengthen the external knowledge activities, the corresponding will pay more attention to the knowledge absorptive capacity, knowledge connection ability and knowledge diffusion ability. Such selective knowledge management enables the innovation performance to be improved comprehensively, thus ensuring the sustainable development of enterprises.

Secondly, China's environment is influenced by the particularity of the system and the traditional culture [11]. Since the reform and opening up, although China's market environment has undergone drastic changes, the market economy system is not perfect. Moreover, "GuanXi" still cannot be avoided in the course of enterprise development. Some people suggest that Chinese enterprises can't grow up without "GuanXi". However, in the long term, under the background of economic globalization, when facing the global market, Chinese enterprises to achieve growth needs a higher quality of top management team and scientific and effective management measures. To strengthen the top management team's relationship with corporate performance, the influence of the "GuanXi " to the enterprise development will be reduced, which requires enterprise attaches great importance to the top management team quality and management ability, strengthen their innovation ability, form their own core competitiveness.

\subsection{Future Perspective}

Although some progress has been made in the research of the top management team, there are still many problems to be solved, and the future research will be further studied. Firstly, the influence mechanism of top management team's management ability of different dimensions on enterprise innovation and development is discussed comprehensively.

So far, a large number of empirical studies have carried out different studies on different dimensions of management ability, such as cognitive ability, management of human resources and the ability of social capital. However, few studies have attempted to analyze the interactions between these capabilities, or to study their synergies. Secondly, the key driving factors and their inner contact mechanism of management ability of managers at different levels are organized. At present, there are few studies to analyze how different levels of management can result. In addition to the top management team, the management ability of middle managers and managers may also have an important influence on enterprise innovation practice. In the future, we can compare the development and mechanism of management capability of different levels of managers to better guide the practice of enterprise innovation and development based on the perspective of management ability.

\section{References}

[1]. Amason A C, Sapienza H J. The effects of top management team size and interaction norms on cognitive and affective conflict. Journal of Management. Vol. 23 (1997) No.4, p. 495-516.

[2]. Q Hu. A new perspective of earnings management behavior research: based on the equity of executive compensation. Business accounting. Vol. 15(2013), p. 98-100.

[3]. Y M Wong, H D Cheng, et al. The heterogeneity of senior management team, strategic dualelement and enterprise performance. Scientific research management. Vol. 36 (2015) No. 11, p. 89-97.

[4]. Benoliel P, Somech A. Functional heterogeneity and senior management team effectiveness. Journal of Educational Administration. Vol. 54 (2016) No. 4, p. 492-512.

[5]. De Dreu, Weingart L R. Task versus relationship conflict, team performance, and team member satisfaction: A meta-analysis. Journal of Applied Psychology. Vol. 88 (2003) No. 4, p. 741-749.

[6]. Jiménez J M R, Fuentes M D M F. Management capabilities, innovation, and gender diversity in the top management team: ann empirical analysis in technology-bases SMEs. Brq Business Research Quarterly. Vol. 19 (2016) No. 2, p. 107-121. 
[7]. Jehn K A, Greer L, Levine S, Szulanski G. The effects of conflict types, dimensions, and emergent states on group outcomes. Group Decision \& Negotiation. Vol. 17 (2008) No. 6, p. 465-495.

[8]. Jia J, Wang G, Zhao X, et al. Exploring the relationship between entrepreneurial orientation and corporate performance: The role of competency of executives in entrepreneurial-oriented corporations. Nankai Business Review International. Vol. 5 (2014) No. 3, p. 326-344.

[9]. Diether G, Sabine B, Eric K. Cross-functionality and innovation in new product development teams: A dilemmatic structure and its consequences for the management of diversity. European Journal of Work \& Organizational Psychology. Vol. 15 (2006) No. 4, p. 431-458.

[10]. Jia J, Wang G, Zhao X, et al. Exploring the relationship between entrepreneurial orientation and corporate performance: The role of competency of executives in entrepreneurial-oriented corporations. Nankai Business Review International.Vol. 5 (2014) No. 3, p. 326-344.

[11]. Liu J, P Fu, Songbo L. Conflicts in top management teams and team/firm outcomes: The moderating effects of conflict-handling approaches. International Journal Of Conflict Management. Vol. 20 (2009) No. 3, p. 228-250. 